\title{
O ASSENTAMENTO BELA VISTA E ALGUMAS REFLEXÕOES SOBRE A RELAÇÃO TRABALHO RURAL E EDUCAÇÃO
}

\author{
Marcos Cassin \\ Universidade de São Paulo (USP) \\ Samila Bernardi do Vale \\ Universidade Federal de São Carlos (UFSCar)
}

\section{RESUMO:}

Tendo como tema geral a relação entre Trabalho Rural e Educação o artigo faz uma análise dos dados obtidos em pesquisa realizada no assentamento Bela Vista do Chibarro, tomando-o como uma importante experiência dos movimentos sociais que lutam pela Reforma Agrária e Educação para os que vivem do trabalho no campo. A escolha deste assentamento como um dos focos de nossa análise ocorreu por dois motivos, por se tratar de um dos primeiros a ser conquistado pela luta dos trabalhadores no estado de São Paulo e o segundo motivo é por ter no seu interior a escola municipal Prof ${ }^{o}$ Hermínio Pagotto, considerada modelo por muitos pesquisadores, professores e estudiosos, e que tem sido referência no que diz respeito a educação específica do campo. Dessa forma, o assentamento e a escola passam a ser um importante objeto de análise das necessidades, ou não, de uma educação diferenciada no/do campo. As pesquisas bibliográficas, visitas a acampamentos e assentamentos e principalmente o acompanhamento durante um ano da rotina do assentamento Bela Vista entre conversas informais com assentados, direção, coordenação, alunos e entrevistas com ex-alunos da escola Prof. Hermínio Pagotto, nos permitiram formulações que apontam para a defesa de uma educação geral, em detrimento de uma educação específica, no campo. O artigo coloca para o debate a importância de uma educação que através dos conhecimentos gerais e científicos permitam com que os alunos compreendam, atuem e contribuam na solução de problemas sociais, políticos, culturais e específicos da produção e da organização do trabalho no campo.

Palavras-chave: Assentamento; Educação; Reforma Agrária; Escola

\section{THE BELA VISTA SETTLEMENT AND SOME REFLECTIONS ABOUT THE RELATIONSHIP RURAL WORK AND EDUCATION}

\begin{abstract}
ABSTRAT:
The relationship between the rural work and the education of the article provides a conducted research in the settlement Bela Vista of Chibarro, taking as an important experience of social moments struggling for agrarian reform and education for those who lives for work in the field. The research of this settlement took as a reference because it is one of the first to be conquered by the struggle of workers in the state of São Paulo and have the Prof: Hermino Pagotto Municipal High school considered a model by many researchers, teachers and students, with a research of specific education reference to the field. In this way, the settlement and the school become a important of analysis of needs, or not, in a different education in or out of the field. From library researches, camps and settlements visits and especially the monitoring for one year about the routine of the Bela Vista settlement between informal conversations with settlers, direction, coordination,
\end{abstract}


students interviews and alumni of the Prof: Herminio Pagotto High school, they pass some formulations that allow us to the reference point of a broad education, rather than a specific education in the field. This article raises for debate the importance of education that through the general and scientific knowledge to enable students to understand,act and contribute to give a solution to social problems, political, cultural and specific production of organization of work in the field.

Keywords: Settlement, Education, Agrarian Reform; School

\section{Introdução}

Esse artigo é resultado da pesquisa que realizamos no assentamento Bela Vista situado no município de Araraquara no estado de São Paulo, tendo como tema geral a relação entre Trabalho Rural e Educação com o objetivo de analisar os impactos das novas tecnologias e das novas formas de organização do trabalho no meio rural, bem como os seus reflexos na formação, qualificação e empregabilidade dos trabalhadores.

Escolhemos o Bela Vista para a nossa análise pois se trata de um assentamento resultado da luta dos trabalhadores Sem Terra, que se constitui em um dos projetos de Reforma Agrária na metade da década de 1980 do século passado, portanto na efervescência dos movimentos socais e da redemocratização do país, depois de 20 anos de ditadura militar.

A localização do assentamento também influenciou na escolha, o município de Araraquara faz parte da região administrativa de Ribeirão Preto, composta por mais de 80 municípios ${ }^{1}$, grande produtora de cana-de-açúcar e laranja e detêm a maior concentração de agroindústrias sucroalcooleira e de cítricos.

Outros dois aspectos que determinaram a escolha foram a escola municipal no interior do assentamento, considerada escola rural padrão, visitada por professores, alunos e pesquisadores, que tem se tornado objeto de várias pesquisas. O segundo aspecto é com relação a produção. Quase na totalidade dos lotes é produzido cana-de-açúcar e fornecida para as usinas de açúcar e álcool.

Esses elementos nos levaram a entender o assentamento Bela Vista como objeto de investigação capaz de apontar algumas reflexões da relação entre organização do trabalho, nesse novo rural brasileiro, e a educação dos domiciliados e dos que trabalham no campo.

Também entendemos que a ampla bibliografia, citada ao final do texto e que não necessariamente aparece no corpo deste trabalho, foram importantes no sentido de subsidiar a discussão aqui proposta, assim como poderá servir como referências para os possíveis leitores, que venham a ter interesse pelo tema.

\section{Pontal do Paranapanema/SP e a Luta pela Terra.}

O marco inicial da atual política de Reforma Agrária ocorreu como fruto da transição democrática, que com a posse do presidente José Sarney em 1985, ainda no final do seu primeiro mandato, sancionou o Primeiro Plano Nacional de Reforma Agrária, que foi o norteador de uma política federal, responsável por assentar muitas famílias de trabalhadores rurais em áreas desapropriadas. Entende-se que esse acontecimento se deu como uma resposta às pressões dos trabalhadores, sendo que no estado de São Paulo 
...Data de 1983, primeiro ano do governo Franco Montoro, uma iniciativa decisiva no sentido de promover experiências de reforma agrária no Estado. Como primeiro governo eleito no Estado após o longo período de governantes pró-ditadura, a gestão Montoro(1983-1986), ela mesma expressão da conjuntura de abertura democrática e, consequentemente, premida pela mobilização crescente dos trabalhadores rurais, responderá às pressões por reforma agrária desenvolvendo uma política de assentamentos que se consolidará nos dias atuais (Ferrante et al. In: Ferrante \& Aly Jr, 2005, p.39).

Analisando o contexto regional do interior do Estado de São Paulo é de fundamental importância destacar as experiências vivenciadas em alguns projetos de assentamentos e principalmente a valorosa mobilização dos trabalhadores em prol da luta pela terra.

Um dos exemplos que pode ser citado, refere-se a luta dos atingidos por barragens no Pontal do Paranapanema, assentados na gleba XV de Novembro no período entre 1983 e 1984, entre os municípios de Euclides da Cunha e Rosana, apresentando-se enquanto símbolo da política estadual. Constata-se atualmente que na região, o Pontal do Paranapanema possui o maior número de assentamentos e de famílias assentadas. Contudo essas conquistas são resultantes de fortes discussões e mobilizações, ao longo de décadas, a respeito da questão fundiária. Portanto, quando se trata de abordar a temática da reforma agrária, a região do Pontal tem representatividade no estado de São Paulo.

Na região conhecida como Pontal do Paranapanema (extremo Oeste Paulista) a questão fundiária tem sido - ao longo de décadas - o ponto fulcral definidor das políticas públicas e ingrediente básico das tensões sociais envolvendo o estado e diferentes classes sociais. A região é, portanto, de importância ímpar quando se aborda a temática da reforma agrária no Estado de São Paulo (Ibid, p.46).

A região destaca-se também por ter em seu histórico, o mais conhecido caso de grilagem de terras do país. Segundo Ferrante et al.,

Ao longo do século XX, posseiros e grileiros disputaram, quase sempre à bala, o território do Pontal. Apesar da flagrante irregularidade que cercou a ocupação do Pontal, seu desenvolvimento econômico seguiu mais ou menos a trajetória de outras regiões do Estado, sobretudo na primeira metade do século passado. Com a crise da cafeicultura, a fragmentação das propriedades e o precoce fim do colonato só acirraram mais as disputas por terras (Ibid, p.46).

A partir da afirmação citada acima percebemos que, apesar de suas irregularidades fundiárias a região do Pontal apresenta um desenvolvimento econômico próximo ao de outras regiões.

Porém, devido à insegurança fundiária e a pouca ação por parte dos governos do período da transição democrática em articular uma forte política de assentamento houve como resposta uma mobilização de diversos segmentos sociais.

Ainda nessa região, a insatisfação por parte dos pecuaristas que se sentiam coagidos por uma possível regularização fundiária expressou-se durante o período do 
Congresso Constituinte (1987-1998) e no surgimento da União Democrática Ruralista. Logo se iniciou um forte embate entre os fazendeiros pecuaristas e os trabalhadores Sem Terra, que teve como ponto de partida uma intensa articulação do Movimento dos Trabalhadores Sem Terra - MST. Em 1990, no primeiro ano do governo Collor, liderado por esse movimento, deu-se início ao mais importante processo de luta pela terra no Estado de São Paulo e se prolonga até hoje.

\title{
Araraquara - Região de Ribeirão Preto
}

Com relação a questão agrária, Araraquara integra a região de Ribeirão Preto de grande desenvolvimento e reconhecida nacional e internacionalmente como a mais importante região do agronegócio do país. De acordo com Ferrante et al.,

\begin{abstract}
...A implantação do PRÓ-ÁLCOOL, em 1975, só estimulou a indústria sucro-alcooleira ali baseada, fazendo crescer de forma acentuadíssima a área plantada de cana, bem como o número de postos de trabalho junto a essa atividade econômica. Ao lado da cultura da cana, um outro Complexo Agroindustrial se consolidava na região, explorando a produção de citrus (in natura e sucos) (Ibid, p.41-42).
\end{abstract}

A exigência de mais terras para atender as necessidades da agroindústria levou a expulsão dos trabalhadores moradores nas fazendas em regime de colonato, para as periferias das cidades. Com essa nova situação dos trabalhadores, as cidades pequenas transformaram-se em cidades dormitórios e os trabalhadores passaram a constituir-se enquanto assalariados temporários nas colheitas de citros e no corte de cana, e dessa forma esses ex-colonos passaram a fazer parte da categoria de "bóias-frias". As péssimas condições de vida que esses trabalhadores enfrentaram, foram os motivos para que a partir de meados de 1980 organizassem fortes mobilizações reivindicando melhores condições de trabalho e salários.

Para Ferrante et al.,
A política de assentamentos rurais desenvolvida nessa região do Estado será claramente uma resposta estatal ao potencial de organização e contestação dos bóias-frias. Sua singularidade, no entanto, deve-se a um entrecruzamento bastante particular da mobilização dos trabalhadores rurais e das conjunturas políticas - tanto no âmbito do governo estadual quanto do governo federal. Trata-se de um campo específico das políticas públicas, no qual um jogo de forças sociais irá, direta ou indiretamente, determinar ações no sentido de assentar famílias de ex-bóias-frias em meio a propriedades empresariais das mais produtivas do país (Ibid, p.42).

Essa nova realidade representada pelos grandes latifúndios de cana-de-açúcar e de citrus, pelo assalariamento e urbanização da força de trabalho do campo levaram a articulações e enfrentamentos dos trabalhadores em oposição aos proprietários de terras, contra o Estado e pela Reforma Agrária, objetivando se livrarem das péssimas condições de vida e trabalho e da nova condição de assalariado imposta.

$\mathrm{Na}$ região de Araraquara esse processo resultou em dois assentamentos organizados entre 1985 e 2003. Foram assentadas por volta de 600 famílias na região, dessas, 377 
famílias se instalaram em lotes agrícolas nas fronteiras dos municípios de Araraquara, Matão e Motuca, sendo esta a maior área de assentamento da região, na Fazenda Monte Alegre.

O outro assentamento da região denominado Bela Vista do Chibarro, foco de nossa análise, é fruto da luta de trabalhadores na ocupação da Usina Tamoio, na qual possuía extensas áreas de cultivo de cana, vivendo seu auge na década de 1950 enquanto complexo agroindustrial. Porém, devido a uma série de problemas a usina passou por uma crise, que culminou com sua falência em 1982.

Foi nesse contexto que em 1984 a usina foi ocupada por trabalhadores Sem-Terras da região de Campinas e pouco tempo depois foram despejados.

\title{
O assentamento Bela Vista
}

Quatro anos após esse episódio por intermédio do Sindicato dos Trabalhadores Rurais de Araraquara as casas de uma das colônias da usina foram ocupadas pelos trabalhadores organizados por essa entidade.

\begin{abstract}
No ano de 1989, ainda não havia sido regularizada a situação dos assentados, os lotes não estavam demarcados e a ocupação da área não era total, visto que poderia comportar 160 famílias e apenas 79 estavam nas terras. Para que o assentamento fosse oficializado se fazia necessário que o governo federal pagasse a indenização pela desapropriação do imóvel. Estas 79 famílias eram chamadas de pioneiras e entraram no assentamento sem que tivessem passado pelo critério de seleção. Neste momento, o sindicato dos empregados rurais de Araraquara tinha pleno domínio sobre a entrada de famílias no assentamento. No mesmo ano, o INCRA executou um cadastramento para entrada de outras famílias. No entanto, acabou por transferir, para esta área da usina "Urupês"2, no ano seguinte, 29 famílias excedentes do projeto Fazenda Reunidas, da cidade de Promissão (Brancaleone, 2002, p.74).
\end{abstract}

Tal atitude resultou nos primeiros conflitos dos assentamentos com o Estado. Houve uma intensa mobilização desses trabalhadores para impedir a entrada dessas novas famílias. Nesse momento a Federação dos Empregados Rurais Assalariados do Estado de São Paulo, FERAESP, mostrava-se muito preocupada com essa transferência, pois estas famílias estavam articuladas com o MST e uma possível disposição em disputar politicamente com o sindicato o controle do assentamento. Depois de muitas negociações as famílias vindas do município de Promissão são assentadas no Bela Vista, este fato demarcou já de início uma divisão de grupos no interior do assentamento.

Essa divisão se estendeu para organização da produção nos lotes, ou seja influenciou nas condições de produção e também na escolha da cultura a ser cultivada. Em 1993 a questão da produção de cana para as usinas de açúcar e álcool foi pautada nos assentamentos. A nova proposta de cultivo de cana-de-açúcar contrapunha-se ao projeto de produção inicial dos assentamentos na região de Araraquara, no início dos anos 1980. Em particular no município de Araraquara, os assentamentos Monte Alegre e Bela Vista trabalhavam com fruticultura e em casos isolados de produção orgânica, mas principalmente com grãos, em especial o milho, que estimulada pelo Instituto de Terras do Estado de São Paulo ( ITESP) foi a primeira cultura a ser produzida em larga escala pelos 
assentados. Tal produção rendeu bons frutos aos trabalhadores, porém em seguida gerou uma estagnação que resultou na inadimplência de muitos assentados.

Por causa das perdas advindas da produção de grãos, os trabalhadores passaram a olhar a possibilidade de se integrar ao complexo agroindustrial sucro-alcooleiro como uma forma de superar suas dificuldades financeiras.

A produção de cana nos assentamentos de Araraquara teve como forte aliado o governo municipal e os setores que se beneficiariam com a substituição da cultura de grãos pela cana. Os assentamentos Monte Alegre e Bela Vista tiveram trajetórias diferentes à introdução da produção de cana, no primeiro, foi mais fácil, não tendo resistência dos assentados. Já no segundo assentamento, a tentativa de implantar o cultivo da cana se deu em 1994, mas foi rejeitada pelas lideranças do assentamento que mobilizaram os assentados contra essa ação e cobraram do INCRA uma atitude contra essa iniciativa, pois o assentamento enquanto concessão do Estado não poderia ser arrendado, portanto, a produção de cana se constituiria em prática ilegal conforme os propósitos da política de reforma agrária.

Depois de grandes embates entre assentados e o INCRA o problema parecia ter sido solucionado, contudo, devido à queda dos preços das culturas de grãos muitos assentados ficaram inadimplentes como já citado acima, com a crise no assentamento em 1997 essa questão voltou a ser pautada no Bela Vista. Nesse período a idéia de plantar cana para a usina provocou grande entusiasmo em grande parte dos trabalhadores, o que resultou na articulação entre a "Associação Independente" e uma usina de Araraquara, consolidando no cultivo da cana-de-açúcar em parte dos lotes do projeto, hoje já em quase todo o assentamento (Ferrante et al, 2005).

As dificuldades, angústias, lutas, resistências, incorporações, desejos e frustrações registradas no caso do assentamento Bela Vista, não representam algo isolado do que se vive nos assentamentos e pré-assentamentos que acompanhamos, como os préassentamentos, hoje assentamentos, Santo Dias, Índio Galdino e Mário Lago no município de Ribeirão Preto/SP , o assentamento Zaqueu Machado em Capixaba/AC, os assentamentos Ezequias dos Reis e Bom Jardim no município de Araguari/MG, Zumbi dos Palmares e Rio das Pedras no município de Uberlândia/MG. Devemos também destacar que as perspectivas, desejos e sonhos que aparecem no início dos projetos de assentamentos são em grande parte cultivados nos acampamentos, pelo menos nos que acompanhamos como, Nova Canudos, Terras Sem Males e Irmã Alberta, todos em São Paulo.

Quanto aos projetos de reforma agrária tem como um dos seus objetivos a formação de assentamentos que desenvolvam a produção agrícola, principalmente de alimentos, e que integrados ao sistema produtivo regional se desenvolvam e todos passaram a viverem felizes para sempre. Mas não é isso que a história do assentamento Bela Vista, e as experiências acima citadas têm revelado.

Ao tentarmos entender os meandros das relações familiares acampadas/assentadas, assim como, das lideranças dos movimentos que lutam pela reforma agrária com o Estado, do latifúndio com os pequenos produtores, da agroindústria com os trabalhadores assalariados foi possível constatarmos que há muitos impasses. As famílias sem capital de investimento e crédito enfrentam grandes dificuldades para produzir em seus lotes e consequentemente são levadas a arrendar suas terras ou produzir matéria-prima para as agroindústrias ou manter-se em condições precárias de subsistência.

Além da preocupação em analisar as condições de vida dos trabalhadores do campo e, também, como o trabalho tem sido organizado no meio rural brasileiro, e mais 
especificamente nos acampamentos e assentamentos, indicamos nesse artigo alguns aspectos da relação entre trabalho e educação no assentamento Bela Vista.

\section{Trabalho e Educação no assentamento Bela Vista.}

A escola municipal do assentamento Bela Vista é uma das representações, entre outras tantas, do meio rural brasileiro marcado por relações de produção capitalistas e uma instituição escolar pública localizada num espaço onde o trabalho se organiza em meio as suas particularidades e com demandas próprias de uma educação universal. Nesse sentido, a escola Prof. Hermínio Pagotto pode se constituir num importante objeto de análise das necessidades, ou não, de uma educação diferenciada no/do campo, como também referência na identificação, investigação e compreensão dos elementos de articulação entre o particular e o universal na relação trabalho rural e educação.

Essa escola tem sido importante objeto de pesquisas e estudos que defendem uma educação escolar especifica para a população do campo, por isso tem se tornado uma das principais referências para os defensores dessa proposta. Contudo, entendemos que essa mesma escola também pode servir as análises que se oponham a educação especifica do campo e defendam uma educação universal embasada pela proposta de escola única que aparece em vários textos de Marx e Engels. Tal proposta compreende o trabalho enquanto principio pedagógico e que a educação deve ser composta pelo ensino intelectual, de ginástica e tecnológico, de modo que possibilite ao sujeito uma formação omnilateral.

Para nós, as pesquisas bibliográficas, visitas aos acampamentos e assentamentos, e principalmente o acompanhamento durante um ano da rotina do assentamento Bela Vista através de conversas informais com assentados, direção, coordenação e alunos da escola Prof. Hermínio Pagotto, além de entrevistas com ex-alunos, nos levaram a convicção de que devemos falar de educação no campo, de uma educação geral que permita o aluno compreender sua particularidade enquanto elemento de uma totalidade. Que o campo, na sociedade capitalista, se organiza a partir das necessidades e da lógica do capital, portanto, impondo uma educação que através dos conhecimentos gerais e científicos permita que o aluno compreenda, atue e contribua na solução de problemas sociais, políticos, culturais específicos da vida e da produção e organização do trabalho no campo.

Nas entrevistas com ex-alunos da escola Prof. Hermínio Pagotto, jovens entre quinze e vinte e cinco anos, buscamos entender as concepções, imagens, expectativas, frustrações e projeções do futuro sobre as relações deles com este novo rural, no que se refere a domicilio, escolaridade, empregabilidade e qualificação profissional.

Foram entrevistados dez jovens, moradores de casas localizadas na vila do assentamento Bela Vista. Todos eles moram neste local a mais de três anos e, os mesmos, sem exceção, freqüentaram a escola do assentamento. Dentre estes jovens cinco estavam cursando o Ensino Médio em escola pública na cidade, dois trabalhavam no próprio assentamento, dois estão sem exercer nenhuma atividade e um estava concluindo o curso de Educação Física em uma Faculdade particular na cidade de Araraquara.

De acordo com suas trajetórias de vida cada jovem pôde relatar um pouco de suas experiências e impressões, tanto da vida no campo e da relação deste com a cidade, quanto à instituição escolar e as perspectivas para o futuro. Com relação à concepção de escola, os alunos apresentam opiniões semelhantes, sempre comparando a escola do campo com a escola da cidade. Uma das questões levantadas por eles refere-se a atenção e atendimento quase individualizado por parte da equipe gestora e de professores da escola do 
assentamento, provavelmente devido ao pequeno número de alunos por sala e da relação escola-família mais próxima. Para Greiciane ${ }^{3}$,

A escola aqui é boa, parece escola particular. Muito boa, acolhe as pessoas. A diferença é que lá na cidade eles não se preocupam muito com a gente, eles estão preocupados em ensinar, mas não estão preocupados se aprendemos ou não. Aqui no assentamento eles já são mais centralizados, eles conversam se a gente tiver algum problema (julho de 2007).

A proximidade das moradias da escola também foi apresentada como um fator que facilita o acesso das crianças e jovens à educação. A estrutura física também teve destaque como fator positivo da escola, por exemplo, a quadra, sala multimídia, cozinha experimental, etc. A fala de uma jovem ilustra muito bem a sua impressão com relação a infra-estrutura da instituição.

É boa a escola daqui do assentamento. Agora tem as salas aqui de baixo, tem multimail, cozinha experimental, é legal essa escola. Aqui é menor, todo mundo se conhece, é perto da nossa casa, acho mais legal a escola daqui, tem uma quadra boa (Márcia, julho de 2007).

Ao serem questionados sobre o ensino os jovens relatam que é bom e que o conteúdo é o mesmo das escolas na cidade, mas em seus relatos afirmam também que alguns dos jovens quando vão para a cidade têm dificuldade de acompanhar o ensino, ou porque não se sentem "ambientalizados", ou pelo ritmo com que os professores direcionam as aulas. Em contrapartida houve afirmações de que o ensino da escola do assentamento é fraco, os conteúdos transmitidos nesta instituição não são os mesmos da escola da cidade e por isso os alunos quando vão para a cidade encontram dificuldade e consequentemente ficam desestimulados, chegando em alguns casos a desistir de frequentar a escola. Cristina conta,

Eu sei de meninos que começaram a estudar lá na cidade só que eles repetiram e desanimaram. Eles estão trabalhando na roça (julho de 2007).

Além das questões levantadas a pouco, entendemos que existem também outros fatores que podem levar os jovens assentados a evasão. Observamos que o ambiente escolar do assentamento é diferenciado, ou seja, a organização do espaço da escola do campo possui uma decoração com elementos da "cultura rural", infra-estrutura privilegiada, além de métodos e instrumentos pedagógicos diferenciados, que tem como proposta educar a partir do contexto do sujeito e reafirmar a "cultura rural". Ao se deparar com a realidade das instituições urbanas o jovem que mora no assentamento e que sempre estudou nesse local, pode ter dificuldade em se sentir parte desse novo contexto.

$\mathrm{Na}$ escola da cidade, na maioria dos casos, há um grande distanciamento na relação professor-aluno ou gestão-aluno, já que a estrutura é outra, as salas possuem grande número de alunos e em alguns casos os estudantes vindos do assentamento são rotulados e colocados em classes cujo rendimento é considerado defasado.

Outro problema nos chamou a atenção, o da relação dos alunos que saem da escola do assentamento, vão para as escolas da cidade, e a lógica na administração do seu tempo de aprendizagem que na grande maioria das vezes não é respeitada na nova escola. 
Entendemos que esse fator pode ter reflexos imediatos na avaliação dos resultados esperados pelos professores, pois essa "demora na adaptação" pode ser entendida por pelos profissionais como "fracasso escolar" acarretando em um desestímulo provocando, em muitos casos, a evasão escolar dos alunos do assentamento. Um exemplo desse fato foi apresentado por Cristina. Ela nos relatou que,

Eu estudava até a oitava série aqui no assentamento. A cidade é muito diferente, porque na cidade tem muito movimento, eu não me dei bem lá, porque as amizades são bem diferentes daqui, tem muitos maconheiros, gente estúpida. E aqui é diferente, porque você aprende uma coisa e lá você aprende outra que você nem tem capacidade, aí eu parei por causa disso. Quando eu fui lá estudar, aprender, aí eu larguei de lá para o ano que vem estudar aqui (julho de 2007).

Segundo os relatos a respeito da perspectiva de futuro dos jovens que não estão exercendo nenhuma atividade, ou aqueles que trabalham no assentamento, como também os que estão frequentando a escola ou faculdade pretendem dar continuidade aos estudos fora do assentamento. Apesar de todos relatarem impressões positivas do assentamento, planejam construir o futuro na cidade, argumentando que no assentamento não há oportunidade para a realização de atividades não agrícolas, além da distância e os poucos horários de ônibus para transportar as pessoas do assentamento para a cidade. Porém, mesmo diante de pretensões da construção de um futuro na cidade foi possível notar na fala de alguns jovens a insegurança e o pensamento de que a realização desta perspectiva está longe de ser alcançada. Essa ideia fica clara, por exemplo, quando um dos entrevistados diz,

A eu acho que a gente que não tem estudo vai ficar desempregado e vai ter pouco recurso, não vai ter como trabalhar para ganhar dinheiro, vai ter que trabalhar para os outros mesmo (Renato, julho de 2007).

A falta de qualificação e recursos financeiros são dois dos principais argumentos dos jovens para sua permanência no assentamento apesar do desejo de ir construir suas vidas na cidade.

E eu queria ir para cidade aprender lá, para estudar, pra trabalhar um dia na frente. Mas só que eu não tenho capacidade para fazer isso, aí eu ajudo minha mãe em casa, vou em roça, ajudo meu pai e vai indo assim (Cristina, julho de 2007).

$\mathrm{Na}$ várias falas notamos que a projeção de um futuro na cidade é criada e não realizada. Nesse sentido podemos verificar uma grande frustração quando o assentado depara-se com a sua realidade, ou seja, poucas condições materiais e de formação que dificultam o seu ingresso no mercado de trabalho fora da atividade agrícola.

Concluímos a partir dessas falas e experiências que devemos pensar uma proposta de educação no campo que possibilite aos filhos dos trabalhadores condições para que compreendam os fundamentos do processo de trabalho, como elemento do processo de produção capitalista, entendam o desenvolvimento histórico e contraditório da sociedade, que se apropriem intelectualmente do que se produziu pela humanidade no campo das artes, da literatura, das ciências naturais e humanas e compreendam a realidade local como 
parte de um todo, ou seja, que possui suas particularidades, porém articulada com o conjunto da sociedade.

\section{Considerações Finais}

A partir do exposto buscamos compreender as lutas pela terra e educação no assentamento Bela Vista no interior de relações de produção capitalistas e em sua particularidade, como assentamento no interior do Estado de São Paulo, com alto nível tecnológico, boa rede de estradas, que facilitam o escoamento da produção e de deslocamento das pessoas e produtos, concentração de capitais, grandes propriedades rurais, agroindústrias e acentuado atendimento de serviços no campo.

Mas mesmo tendo como objeto de análise a particularidade do Bela Vista, ela nos permitiu a apropriação de referências sobre a relação da nova organização do trabalho no campo e a educação escolar dos filhos dos trabalhadores, nos permitindo inferir que a organização do trabalho rural não exige uma educação diferenciada no que diz respeito ao ensino regular, educação básica, ainda mais a partir de meados da década de 1980 do século passado com mecanização, informatização, insumos químicos e biológicos e o aparecimento das agroindústrias aumentando as oportunidades de acesso a bens de consumo duráveis, as melhorias no transporte, lazer, comunicação, empregabilidade, etc, aproximando os ritmos de vida do meio rural do urbano com suas facilidade, dificuldades e contradições.

É importante que ao fazermos este conjunto de análises tenhamos a dimensão de que as diferenças não estão entre campo e cidade, mas no atendimento das diferentes classes. Portanto o difícil acesso a educação e o distanciamento da cultura escolar das realidades vividas não é uma condição apenas dos filhos de assentados ou de produtores familiares, mas também das crianças e jovens oriundos de bairros periféricos, de favelas e cortiços das cidades.

As diferentes condições de atendimento escolar às diferentes classes sociais já se apresentam na atribuição de aulas e classes aos professores. Geralmente são poucos os profissionais que tem como opção trabalhar em escolas de periferia ou localizadas na área rural. A essas escolas se destinam, em sua maioria, os profissionais que possuem formação recente e pouca prática docente, ou ainda, docentes em formação. Além de todas as dificuldades no interior das escolas que atentem as classes sociais subalternas, as crianças não contam com a contribuição das famílias nos afazeres escolares dificultando a interiorização da cultura exigida no ambiente escolar. A linguagem utilizada no ambiente familiar não condiz com a norma culta, já que na maioria das vezes os membros dessas famílias são de baixa escolaridade. Outro fator que favorece esta relação de distanciamento família/escola é a rotina exaustiva de trabalho da maioria dos familiares e em muitos casos da própria criança e adolescente.

Portanto, as crianças originárias destas classes, na maioria das vezes, ingressam na escola sem as noções prévias da cultura escolar, diferentemente das crianças de classe média e alta que incorporam em seu cotidiano familiar, práticas e conhecimentos culturais extra escolares, como por exemplo, teatro, cinema, música etc. Além desses fatores levantados acima existe a falta de acompanhamento dos familiares nas tarefas propostas pela escola, pois os pais em grande parte são analfabetos, ou analfabetos funcionais, e a rotina de trabalho muitas vezes não permite a disponibilidade de tempo para atender as necessidades dos filhos. Nesse sentido, podemos avaliar que o nível econômico, social e cultural das famílias é um dos determinantes no êxito, ou fracasso, das crianças em 
ambiente escolar da forma como hoje este está organizado. Esse fato pode explicar o porquê do grande número de reprovações e evasões em escolas onde o público alvo são filhos de trabalhadores assentados, favelados etc. Portanto, entendemos que as diferenças entre dois universos escolares não estão entre a cidade e o campo, mas, entre as escolas que atendem os filhos da elite e as escolas que atendem os filhos dos trabalhadores. Ou seja, a educação escolar tem caráter de classe, sendo oferecida diferenciadamente para as classes que detêm os meios de produção e as classes que não detêm e vive do seu trabalho.

\section{Bibliografia}

BRANCALEONE, Ana Paula. Do rural ao urbano: o processo de adaptação de alunos moradores de um assentamento rural à escola urbana, 2002. Dissertação (Mestrado em Psicologia) FFCLRP/USP. Ribeirão Preto.

ELIAS, Denise. Globalização e Agricultura: A região de Ribeirão Preto. São Paulo: Editora da Universidade de São Paulo, 2003. (Coleção Campi).

FERRANTE, Vera L. S. B. \& ALY Jr., Osvaldo. Assentamentos Rurais: impasses e dilemas (uma trajetória de 20anos). São Paulo: INCRA - Superintendência Regional de São Paulo, 2005.

IANNI, Octavio. Origens Agrárias do Estado Brasileiro. São Paulo: Brasiliense, 2004.

MARTINS, José de Souza. Reforma Agrária: O impossível Diálogo. São Paulo: Editora da Universidade de São Paulo, 2000.

MARX, Karl \& ENGELS, Friedrich. Crítica da educação e do ensino. Lisboa, Moraes, 1978.

MORISSAWA, Mitsue. A História da Luta pela Terra e o MST. São Paulo: Expressão Popular, 2001.

NOSELLA, Paolo. A escola de Gramsci. $3^{\text {a }}$ ed. São Paulo: Cortez, 2004.

SILVA, José Graziano da. A Nova Dinâmica da Agricultura Brasileira. $2^{\mathrm{a}}$ ed. Campinas: UNICAMP. IE, 1998.

2002.

. O Novo Rural Brasileiro. $2^{\mathrm{a}}$ ed. Campinas: UNICAMP. IE,

. O que é Questão Agrária. $13^{\mathrm{a}}$ ed. São Paulo: Editora

Brasiliense, 1986. (Col. Primeiros Passos, 18).

. Sobre a delimitação do rural e do urbano no Brasil: testando

as aberturas geográficas das novas Pnads. In: www.eco.unicamp.br acesso em: $02 / 03 / 2007$

Editora da UFRGS, 2003.

Tecnologia e Agricultura Familiar. 2a ed. Porto Alegre:

SILVA, José Graziano da \& DEL GROSSI, Mauro Eduardo. O Novo Rural Brasileiro: uma atualização para 1992-98. In: www.eco.unicamp.br acesso em: 02/03/2007 
VEIGA, José Eli. O que é Reforma Agrária. São Paulo: Abril cultural: Editora Brasiliense, 1984. (Col. Primeiros Passos, 9).

WEBER, Marx. Capitalismo e Sociedade Rural na Alemanha. In: Ensaios de Sociologia. $5^{\text {a }}$ edição. Rio de janeiro: LTC, sd.

WOLFFENBÜTTEL, Andréa. Uma Escola de Raiz. In:

http://www.desafios.org.br/Edicoes/10/artigo12954-1.asp?o=s Acesso em: 27/05/2007

www.ibge.gov.br/home/ Acesso em: 10/04/2007

Notas

${ }^{1}$ Segundo os dados do Seade de 1983.

${ }^{2}$ Urupês é o nome fictício que a autora Brancaleone dá a Usina Tamoio.

${ }^{3}$ Os nomes citados ao longo das entrevistas são fictícios, para que possamos preservar os sujeitos entrevistados.

Recebido em 30/12/2010

Aprovado em 18/2/2011 